\title{
Study to identify dietary factors and life style patterns responsible for gall stones among north Karnataka patients
}

\author{
K. Arvind ${ }^{1}$, Kalghatgi S. ${ }^{2}$, Kulkari M. ${ }^{3}$, Vipin T. ${ }^{4}$, Kamat V. ${ }^{5}$ \\ ${ }^{1}$ Dr. K Aravind, Associate Professor, Department of Surgical Gastroenterology, Karnataka Institute of Medical Sciences, \\ Hubli, Karnataka. ${ }^{2}$ Dr. Kalghatgi Suhas, Assistant Professor, ${ }^{3}$ Dr MukundKulkarni, ${ }^{4}$ Dr Vipin T, ${ }^{5}$ Dr Vijay Kamat, All \\ authors are affiliated with Department of Surgical Gastroenterology, Karnataka Institute of Medical Sciences, Hubli, \\ Karnataka, India
}

Address for Correspondence: Dr. Kalghatgi Suhas, Assistant Professor, Department of Surgical Gastroenterology, Karnataka Institute of Medical Sciences, Hubli, Karnataka. E-mail: dr. suhasrk@gmail.com

\begin{abstract}
Introduction:Gall stone disease is common problem in Indian subcontinent.Cholelithiasis has increasingly become a major cause of morbidity, leading to hospital admission and surgery in the developing world. There has also been a remarkable shift in the trend of gall-stone disease from middle aged, fertile, fat females to young asthenic females in their twenties. Material and methods: Descriptive analytic design study was conducted using questionnaire to collect required data. The study focused on the assessing risk factors of cholelithiasisamongstpatients admittedfor cholecystectomy. Cases $(n=39)$ from all age groups and both sexes with sonographically proven gallstoneswere included. Age- and sex-matched controls $(n=40)$ were chosen from among ward inmates admitted for other reasons. Univariate and multivariate logistic regression analyses were performed for selected sociodemographic, dietary, and lifestyle-related variables. Results: Out of the 79 subjects, 39 were cases and remaining 40 were controls. The mean age of 45.56 years was slightly higher in cases, as compared to 40.20 in controls in which females are more than males. The proportion of smoking participants at cases were $10.3 \%$ and the proportion was $5.0 \%$ at controls. The proportion of alcohol participants at cases were $10.3 \%$ and controls were $7.5 \%$ in the study population. The proportion of tobacco intake participants were $28.2 \%$ at cases and $32.5 \%$ at controls. The mean BMI at cases was 22.54 and the mean BMI was 20.32 at controls which was statistically significant with a $\mathrm{P}$ value 0.02 .The mean WH ratio was 1.34 at cases and 0.81 at controls. The mean oil intake per month at cases were $650.79 \pm 346.48$ and $617.5 \pm 285.0$ at controls. The mean salt intake per month at cases and controls were $10.61 \pm 5.28$ and $13.77 \pm 7.78$ respectively. The mean non veg intake per month at cases were $4.20 \pm 6.53$ and $1.89 \pm 2.14$ at controls. Conclusion:Gallstone disease is frequent among females and elderly males. Significant predictor variables are abdominal adiposity, inadequate physical activity, and high intake of saturated fats; thus representing high risk lifestyles and yet amenable to primary prevention.
\end{abstract}

Keywords:Gallstone, Lifestyle, Risk factors

\section{Introduction}

Epidemiological studies show that gallstones formation is a complex multifactorial disease associated with dietary habits, overweight, sex, and family history of gallstone disease, with no evidence of racial or climatological factors resulting in the increase in cholelithiasis $[1,2,3]$.

Once considered a disease of the Western world and the affluent, cholelithiasis has increasingly become a major cause of abdominal morbidity, leading to hospital admission in the developing world [4]. Many recent studies have shown that gallstone disease is related to age, sex, and metabolic disorders, such as obesity,

Manuscript Received: $10^{\text {th }}$ September 2017

Reviewed: $16^{\text {th }}$ September 2017

Author Corrected: $23^{\text {rd }}$ September 2017

Accepted for Publication: 30 $0^{\text {th }}$ September 2017
Dyslipidemia (hypertriglyceridemia), and type 2 diabetes $[5,6,7]$. The pathogenesis of gallstone disease is suggested to be multifactorial and probably develops from complex interactions between many genetic and environmental factors $[8,9]$.

Age, female sex, obesity, dyslipidemia, diabetes mellitus, metabolic syndrome, rapid weight loss, total parenteral nutrition, chronic disease including Crohn disease, cystic fibrosis, and chronic liver disease, and drugs including octreotide, ceftriaxone, and statin were previously identified as risk factors for asymptomatic cholelithiasis[10]. 


\section{Original Research Article}

From a public health standpoint, it is not only important to study the background prevalence of gallstone disease regionally, but to also explore the demographic and biological markers related to the development of gallstone disease. If we can predict which factors contribute to the development of gallstone disease, we can prevent it by controlling these factors. The present study was designed to explore the potential risk factors for gallstone disease and to improve the understanding of the overall pathogenesis of this disease.

\section{Material and Methods}

Patients admittedwith a diagnosis of gall stones in the department of general surgery, Karnataka Institute of Medical Sciences, Hubliover a period of 18 months from December 2014 to June 2016 were included in study.

Study Design- Descriptive analytic design study was conducted using questionnaire to collect required data.

Inclusion criteria- patients with definitive diagnosis of gallstone based on ultra sonogram of abdomen

Exclusion criteria- Patients less than 15 yrsold, overt hemolysis, co morbidities like pancreatitis and those who are not willing for participation in the study

Collection of data- Controls are age and sex matched asymptomatic subjects with a normal gall bladder from same population coming to KIMS Hubli for regular health check up or admitted in other department, taking ultra sonogram for purposes not related with gall stone.Cases $(n=39)$ from all age groups and both sexes with sonographically proven gallstones were recruited over a duration of 18 months from the surgical wards of a KIMS, HUBLI Hospital from December 2014 to 2016. Modes of presentation were also noted among cases. Age- and sexmatched controls $(n=40)$ were chosen from among ward inmates admitted for other reasons. Univariate and multivariate logistic regression analyses were performed for selected sociodemographic, dietary, and lifestylerelated variables.

Data obtained from both cases and controls includes demographic characteristics (age, gender, literacy occupation, religion, family size, type of house), life style variables (alcohol, smoking).BMI, co-morbid condition like diabetes, hypertension .Dietary details on the weekly consumption of cereals, use of tamarind, vegetables fruits,beveragesetc with type of food item with frequency (spicy or fried) also was collected.Written informed consent will be taken from patient for pre-operative evaluation, surgical procedure, post operative evaluation and willingness to participate in study.Approved proformas was used for collecting demographic data, clinical data, preoperative evaluation, andsonographic findings.

Statistical analysis- Descriptive analysis was done using, mean and standard deviation for quantitative variables, frequency and percentages for categorical variables. The comparison between explanatory and outcome variables was assessed by comparing the means for quantitative variables and proportions for categorical variables. Independent sample t-test and chi square test were used appropriately to assess the statistical significance. Appropriate graphs like, bar diagram and pie diagram were used to visually represent the data. IBM SPSS version 21 was used for statistical analysis

\section{Results}

A total of 79 subjects were included in the final analysis.

Table-1: Descriptive analysis of cases \& controls in study group $(\mathrm{N}=79)$

\begin{tabular}{|c|c|c|}
\hline Cases \& Controls & Frequency & Percent \\
\hline Cases & 39 & 49.4 \\
\hline Controls & 40 & 50.6 \\
\hline
\end{tabular}

Out of the 79 subjects, 39 were cases and remaining 40 were controls. (Table 1)

Table-2: Comparison of Age and gender parameters across the two study groups $(\mathrm{N}=79)$

\begin{tabular}{|c|c|c|c|}
\hline Parameter & Cases(N=39) & Controls(N=40) & P-value \\
\hline Age & $45.56 \pm 14.65$ & $40.20 \pm 15.79$ & 0.12 \\
\hline Female: Male & $1: 0.25$ & $1: 0.29$ & 0.83 \\
\hline
\end{tabular}

Both the study groups were comparable with respect to various socio demographic parameters like age and gender. The mean age of 45.56 years was slightly higher in cases, as compared to 40.20 in controls. But the difference in age across the two study groups was statistically not significant. (Table 2) and female to male ratio was 1:0.25 in cases and 1:0.29 in controls. 
Table-3: Comparison of various habits across the two study groups $(\mathrm{N}=79)$

\begin{tabular}{|c|c|c|c|c|}
\hline Parameter & Cases(N=39) & Controls(N=40) & Chi square Value & P-value \\
\hline Smoking & $4(10.3 \%)$ & $2(5.0 \%)$ & 0.77 & 0.37 \\
\hline Alcohol & $4(10.3 \%)$ & $3(7.5 \%)$ & 0.18 & 0.66 \\
\hline Tobacco & $11(28.2 \%)$ & $13(32.5 \%)$ & 0.17 & 0.67 \\
\hline Betalnut & $21(53.8 \%)$ & $21(52.5 \%)$ & 0.014 & 0.90 \\
\hline
\end{tabular}

The proportion of smoking participants at cases were $10.3 \%$ and the proportion was $5.0 \%$ at controls which was not statistically significant. The proportion of alcohol participants at cases were $10.3 \%$ and controls were $7.5 \%$ in the study population. The proportion of tobacco intake participants were $28.2 \%$ at cases and $32.5 \%$ at controls.

Table-4: Comparison of anthropometric parameters across the two study groups $(\mathrm{N}=79)$

\begin{tabular}{|c|c|c|c|}
\hline Parameter & Cases(N=39) & Controls(N=40) & P-value \\
\hline BMI & $22.54 \pm 4.47$ & $20.32 \pm 3.96$ & 0.02 \\
\hline WH Ratio & $1.34 \pm 3.11$ & $0.81 \pm 0.05$ & 0.29 \\
\hline
\end{tabular}

The mean BMI at cases was 22.54 and the mean BMI was 20.32 at controls which was statistically significant with a P value 0.02. The mean WH ratio was 1.34 at cases and 0.81 at controls in study population which was statistically not significant (P value $=0.05)$

Table-5: Comparison of co-morbidities across the two study groups $(\mathrm{N}=79)$

\begin{tabular}{|c|c|c|c|c|}
\hline Co-morbidities & Cases(N=39) & Controls(N=40) & Chi square value & P-value \\
\hline Diabetes Mellitus & $6(15.4 \%)$ & $33(84.6 \%)$ & 0.518 & 0.472 \\
\hline Hypertension & $8(20.5 \%)$ & $3(7.5 \%)$ & 3.63 & 0.163 \\
\hline
\end{tabular}

In diabetes mellitus the proportion of participants categorized as cases were $15.4 \%$ and controls were $84.6 \%$ respectively. At hypertension the proportion of participants categorized as cases were $20.5 \%$ and controls were $7.5 \%$ in study population. The association between the two groups were statistically not significant. ( $\mathrm{P}$ Value $=0.05$ ).

Table-6: Comparison of DIET parameters across the two study groups $(\mathrm{N}=79)$

\begin{tabular}{|c|c|c|c|c|}
\hline Parameter & $\operatorname{Cases}(\mathrm{N}=39)$ & Controls $(\mathrm{N}=40)$ & Chi square value & P-value \\
\hline Cereals & $39(100 \%)$ & $40(100 \%)$ & - & - \\
\hline $\begin{array}{c}\text { Vegetables } \\
\text { - 2-3 times } \\
\text { - Daily }\end{array}$ & $\begin{array}{l}\text { - } 1(2.6 \%) \\
\text { - } 38(97.4) \\
\end{array}$ & $\begin{array}{c}\text { - } 0(0.0 \%) \\
\text { - } 40(100 \%)\end{array}$ & 1.039 & 0.308 \\
\hline $\begin{array}{l}\text { Pulses } \\
\text { - } 2-3 \text { times } \\
\text { - Daily }\end{array}$ & $\begin{array}{cc}\text { - } \quad 1(2.6 \%) \\
\text { - } 38(97.4 \%)\end{array}$ & $\begin{array}{cc}\text { - } & 0(0.0 \%) \\
\text { - } & 40(100 \%)\end{array}$ & 1.039 & 0.308 \\
\hline Oil per month & $650.79 \pm 346.48$ & $617.5 \pm 285.0$ & - & 0.64 \\
\hline Salt Per Month & $10.61 \pm 5.28$ & $13.77 \pm 7.78$ & - & 0.03 \\
\hline Sugar intake in Gms & $28.66 \pm 13.62$ & $32.82 \pm 18.43$ & - & 0.25 \\
\hline Non veg Per Month & $4.20 \pm 6.53$ & $1.89 \pm 2.14$ & - & 0.04 \\
\hline Tea per Day & $2.17 \pm 0.94$ & $2.34 \pm 0.81$ & - & 0.42 \\
\hline Fried food per month & $8.87 \pm 6.13$ & $4.43 \pm 2.79$ & - & $<0.001$ \\
\hline Pepper spicy food & $23(59 \%)$ & $9(22.5 \%)$ & - & 0.003 \\
\hline Fruits per month & $7.05 \pm 9.23$ & $7.67 \pm 9.63$ & - & 0.77 \\
\hline
\end{tabular}

The proportion of cereals intake daily at cases and controls were $100 \%$ in study population. The mean oil intake per month at cases were $650.79 \pm 346.48$ and $617.5 \pm 285.0$ at controls. The mean salt intake per month at cases and controls were $10.61 \pm 5.28$ and $13.77 \pm 7.78$ respectively. The mean non veg intake per month at cases were $4.20 \pm 6.53$ and $1.89 \pm 2.14$ at controls. 


\section{Discussion}

Cholelithiasis (the presence of one or more gallstones in the bladder) represents a significant burden for healthcare systems worldwide [10] and is one of the most common disorders among patients presenting to emergency rooms with abdominal discomfort--e.g., epigastric pain, nausea, vomiting, loss of appetite [11]. Ethnicity and family traits are recognized as contributing factor [11]

Gallstone was typically described as disease of females in their forty. Variations are there from place to place and are changing with time also. The gallstones were predominantly noticed in females with female to male ratio in cases where 1:0.25in our study. Sung Bum Kim et al [12] study donein age $<40$ years, significantly higher prevalence of asymptomatic cholelithiasis was observed in females compared with males $(2.7 \%$ vs. $1.9 \%$, $P=0.020$ ), whereas males showed significantly higher prevalence than females at age over 50 years $(6.2 \%$ vs. $5.1 \%, P=0.012)$. The mean age of males and females was $47.7 \pm 10.5$ years and $46.7 \pm 11.4$ years, respectively $(P<0.001)$. Proportion of obesity was $39.0 \%$ $(7014 / 17,966)$ in male examinees and $18.7 \%$ $(2357 / 12,578)$ in female examinees $(P<0.001)$. Central obesity was observed in $8522(47.4 \%)$ male examinees and $4225(33.8 \%)$ female examinees $(P<0.001)$. Hypertriglyceridemia was observed in 6370 (35.5\%) male examinees and $1600 \quad(12.7 \%)$ female examinees $(P<0.001)$. High fasting glucose was observed in 2235 $(12.4 \%)$ males and $710(5.6 \%)$ females $(P<0.001)$, which is similar to our study.

In our study, the mean BMI of cases was 22.54 and the mean BMI was 20.32 of controls which was statistically significant with a $\mathrm{P}$ value 0.02 .The mean $\mathrm{WH}$ ratio was 1.34 at cases and 0.81 at controls in study population which was statistically not significant $(\mathrm{P}$ value= 0.05).Similar to our study,Hui Sun et al [13] found the prevalence of gallstone disease among the study subjects was $10.7 \%$ (384/3573): $9.9 \%$ in men and $11.6 \%$ in women. The results of univariate analysis of individual factors and their association with gallstone disease among the 3573 subjects. The factors significantly associated with gallstone disease were an age of 40-64 years and an age $\geq 65$ years. Slagter SN et al [14] foundprevalence of gall stones increased with higher BMI levels. A total of $64 \%$ of obese men and $42 \%$ of obese women had gallstones. Current smoking was associated with a higher risk of gallstones in both sexes and all BMI classes (odds ratio 1.7 to 2.4 for men, 1.8 to 2.3 for women, all $P$ values $<0.001)$. Current smokers had lower levels of HDL cholesterol and apoA1, higher levels of triglycerides and apoB, and higher waist circumference than non-smokers (all $\mathrm{P}<0.001$ ). Smoking had no consistent association with blood pressure or fasting blood glucose. In all BMI classes, we found a dose-dependent association of daily tobacco consumption with gallstones prevalence as well as with lower levels of HDL cholesterol, higher triglyceride levels and lower ratios of HDL cholesterol/ apoA1 and, only in those with BMI $<30$, LDL cholesterol/apoB (all $\mathrm{P}<0.001$ ). ShabanzadehDM[15] et al Participants with no gallstones at baseline and with at least one re-examination were followed-up completely (mean 11.6 years, $\mathrm{N}=2848$ ). The overall cumulative incidence of gallstones was $0.60 \%$ per year. Independent positive determinants for incident gallstones were age, female sex, non-high density lipoprotein (non-HDL) cholesterol, and gallbladder polyps. In addition, BMI was positively associated in men, similar to our study.

In our study, the proportion of smoking participants at cases were $10.3 \%$ and the proportion was $5.0 \%$ at controls which was not statistically significant. The proportion of alcohol participants at cases were $10.3 \%$ and controls were $7.5 \%$ in the study population. The proportion of tobacco intake participants were $28.2 \%$ at cases and $32.5 \%$ at controls

Rehm J et al[16] confirms the importance of alcohol use as a risk factor for disease and injuries; for some health outcomes, more than one dimension of use needs to be considered. Epidemiological studies should include measurement of heavy drinking occasions in line with biological knowledge.

Kharga B et al [17] concluded that it's not only the overweight or obese patients who develop symptomatic cholelithiasis but also the individuals with normal BMI. The risk of symptomatic cholelithiasis increases with every increase in BMI. Risk of symptomatic cholelithiasis also increases in women and as the age advances. An estimated $20 \%$ of adults over 40 years of age and $30 \%$ of those over age 70 have biliary calculi. During the reproductive years, the female-to-male ratio is about $4: 1$, with the sex discrepancy narrowing in the older population to near equality. The risk factors predisposing to gallstone formation include obesity, diabetes mellitus, estrogen and pregnancy, hemolytic diseases, and cirrhosis [18].

Several studies have reported on dietary and life style changes as risk factors for cholesterol GS. The protective factors include poly- and monounsaturated fat, fiber, and caffeine. Consuming a vegetarian diet was also associated with decreased risk. Nutritional supplements that may prevent cholesterol GS include vitamin C, soy lecithin, 
and iron. Sedentary lifestyle, diet rich in animal fats (cholesterol, saturated fat, transfatty acids)and refined sugar, low in vegetable fats, fiber, and legumes are reported as significant risk factors for cholesterol GS [21]. There are few studies on dietary risk factors for gall stones.In our study we found that the proportion of cereals intake daily at cases and controls were $100 \%$ in study population. The mean oil intake per month at cases were $650.79 \pm 346.48$ and $617.5 \pm 285.0$ at controls. The mean salt intake per month at cases and controls were $10.61 \pm 5.28$ and $13.77 \pm 7.78$ respectively. The mean non veg intake per month at cases were $4.20 \pm 6.53$ and $1.89 \pm 2.14$ at controls.

Eric M. Lander et al [19] found that In multivariate analysis, women in the highest quintile of energy-adjusted vegetable protein intake $(>24.0 \mathrm{~g} / \mathrm{d})$ had a lower risk of gallbladder disease ( $\mathrm{HR}, 0.87 ; 95 \% \mathrm{CI}, 0.81-0.93)$ as compared to women in the lowest quintile $(<16.3 \mathrm{~g} / \mathrm{d})$ $\left(P_{\text {trend }}<0.001\right)$. Total protein intake was modestly protective against gallbladder disease $\left(P_{\text {trend }}<0.021\right)$. Animal protein intake was not associated with gallbladder disease risk. The protective effect of vegetable protein held stable only for women without history of diabetes (HR, 0.86; 95\% CI, 0.80-0.92) and without recent weight loss (HR, 0.88; 95\% CI, 0.80-0.97).It is known that plant based diets contain fewer dietary triglycerides and cholesterol than animal-based diets. Cholesterol stone formation, constituting approximately $80 \%$ of gallstone cases, occurs when cholesterol formation continually exceeds the solubilizing capacity of bile. Saturated fats are known to have the largest effect on cholesterol synthesis [20]. Therefore, diets rich in cholesterol and saturated fats may be elevating cholesterol to levels beyond bile solubilization capacity, a known pathogenesis of cholesterol gallstones [21]. Increased physical activity and lower BMI have both been well associated with significantly lower risk of symptomatic gallstones [22,23].

The metabolic syndrome is defined by the presence of at least 3 features out of: abdominal obesity, high blood pressure, high fasting glucose, increased triglyceride levels and reduced HDL levels [24]. Both the metabolic syndrome and diabetes mellitus are risk factors for gallstone disease [25]. The metabolic syndrome has also been associated with stone complications [26]. Insulin resistance predisposes to cholesterol gallstone formation [27].Suggesting altered cholesterol and bile salt metabolism. Hepatic insulin resistance may act by enhancing hepatic cholesterol secretion, depressing bile salt synthesis and/or impairing gallbladder motility [28].

An aging population plus the rising epidemic of obesity and the metabolic syndrome are certain to aggravate the frequency and complications of gallstone disease. Identifying risk factors that can be altered (i.e., extreme obesity, rapid weight loss, sedentary lifestyle, and key dietary factors) should provide an opportunity to prevent cholelithiasis.

\section{Conclusion}

The study shows that increasing age, female sex, obesity, diabetes mellitus, smoking, alcohol, high calorie intake, and non-vegetarian diet are major risk factors of gallstone disease.Efforts should be directed toward preventing disease through modifying preventable risk factor like smoking, non-vegetarian- diet, high calorie intake.

Conflict of interest: None declared.

Funding: Nil, Permission from IRB: Yes

\section{References}

1. Alsaif MA. Variations in dietary intake between newly diagnosed gallstone patients and controls. Pakistan J Nut. 2005;4(1):1-7.

2. Ahmed A, Cheung RC, Keeffe EB. Management of gallstones and their complications.Am Fam Physician. 2000 Mar 15;61(6):1673-80, 1687-8.

3. Abu-Eshy SA, Mahfouz AA, Badr A, El Gamal MN, Al-Shehri MY, Salati MI, Rabie ME. Prevalence and risk factors of gallstone disease in a high altitude Saudi population.EastMediterr Health J. 2007 Jul-Aug;13 (4): 794-802.

4. Shaffer EA. Gallstone disease: Epidemiology of gallbladder stone disease.BestPract Res Clin Gastroenterol. 2006;20(6):981-96.

5. Katsika D, Tuvblad C, Einarsson C, Lichtenstein P, Marschall HU. Body mass index, alcohol, tobacco and symptomatic gallstone disease: a Swedish twin study.J Intern Med. 2007 Nov;262(5):581-7. Epub 2007 Oct 1.

6. Tsai CJ, Leitzmann MF, Willett WC, Giovannucci EL. Weight cycling and risk of gallstone disease in men.Arch Intern Med. 2006 Nov 27;166(21):2369-74.

7. Park YH, Park SJ, Jang JY, Ahn YJ, Park YC, Yoon YB, Kim SW. Changing patterns of gallstone disease in Korea.World J Surg. 2004 Feb;28(2):206-10. Epub 2004 Jan 8 .

8. Marschall HU, Einarsson C. Gallstone disease.J Intern Med. 2007 Jun;261(6):529-42.

9. Stinton LM, Myers RP, Shaffer EA,Méndez-Sánchez $\mathrm{N}$, Chavez-Tapia NC, Uribe M. The role of dietary fats in 


\section{Original Research Article}

the pathogenesis of gallstones. Front Biosci. 2003;8:e420e427.

10. Bodmer M, Brauchli YB, Krahenbuhl S, Jick SS, Meier CR: Statin use and risk of gallstone disease followed by cholecystectomy. JAMA. 2009, 302 (18): 2001-2007.

10.1001/jama.2009.1601.jamanetwork.com/journals/j

11. Hung SC, Liao KF, Lai SW, Li CI, Chen WC. Risk factors associated with symptomatic cholelithiasis in Taiwan: a population-based study.BMC Gastroenterol. 2011 Oct 17;11:111. doi: 10.1186/1471-230X-11-111.

12. Sung Bum Kim Sex differences in prevalence and risk factors of asymptomatic cholelithiasis in Korean health screening examineeMedicine (Baltimore). 2017 Mar; 96(13): e6477. Published online 2017 Mar 31.

13. Sun H, Tang H, Jiang S, Zeng L, Chen EQ, Zhou TY, Wang YJ. Gender and metabolic differences of gallstone diseases.World J Gastroenterol. 2009 Apr 21;15(15):1886-91.

14. Slagter $\mathrm{SN}^{1}$, van Vliet-Ostaptchouk JV Associations between smoking, components of metabolic syndrome and lipoprotein particle size.BMC Med. 2013 Sep 3;11:195. BMC Med. 2013 Sep 3;11:195

15. Shabanzadeh DM, Sørensen LT, Jørgensen T. Determinants for gallstone formation - a new data cohort study and a systematic review with meta-analysis.Scand J Gastroenterol. 2016 Oct;51(10):1239-48. doi: 10.1080/00365521.2016.1182583. Epub 2016 May 27.

16. Rehm J, Gmel GE Sr, GmelGThe relationship between different dimensions of alcohol use and the burden of disease-an update. Addiction. 2017 Jun;112(6):968-1001.

17. Kharga $\mathrm{B}^{1}$, Sharma BKObesity Not Necessary, Risk of Symptomatic Cholelithiasis Increases as a Function of BMI. J ClinDiagn Res. 2016 Oct;10(10):PC28-PC32.

18. Schirmer BD, Winters KL, Edlich RF. Cholelithiasis and cholecystitis.J Long Term Eff Med Implants. 2005; 15(3):329-38.
19. Eric M. Lander, ${ }^{a}$ Betsy C. Wertheim Vegetable protein intake is associated with lower gallbladder disease risk: findings from the Women's Health Initiative prospective cohort Prev Med. Author manuscript; available in PMC 2017 Jul 1.Published in final edited form as:Prev Med. 2016 Jul; 88: 20-26. w

20. Hu FB, Manson JE, Willett WC. Types of dietary fat and risk of coronary heart disease: a critical review.J Am Coll Nutr. 2001 Feb;20(1):5-19.

21. Acalovschi M. Cholesterol gallstones: from epidemiology to prevention.Postgrad Med J. 2001 Apr;77(906):221-9.

22. Banim PJ, Luben RN, Wareham NJ, Sharp SJ, Khaw KT, Hart AR. Physical activity reduces the risk of symptomatic gallstones: a prospective cohort study. Eur J GastroenterolHepatol. 2010 Aug; 22(8):983-8.

23. Erlinger S. Gallstones in obesity and weight loss.Eur J Gastroenterol Hepatol. 2000 Dec;12(12):1347-52.

24. Eckel RH, Grundy SM, Zimmet PZ. The metabolic syndrome.Lancet. 2005 Apr 16-22;365(9468):1415-28.

25. Méndez-Sánchez N, Chavez-Tapia NC, Motola-Kuba D, Sanchez-Lara K, Ponciano-Rodríguez G, Baptista H, Ramos MH, Uribe M. Metabolic syndrome as a risk factor for gallstone disease.World J Gastroenterol. 2005 Mar 21; 11(11):1653-7.

26. Ata N, Kucukazman M, Yavuz B, Bulus H, Dal K, Ertugrul DT, Yalcin AA, Polat M, Varol N, Akin KO, Karabag A, NazligulYthe metabolic syndrome is associated with complicated gallstone disease.Can J Gastroenterol. 2011 May; 25(5):274-6.

27. Nervi F, Miquel JF, Alvarez M, Ferreccio C, GarcíaZattera MJ, González R, Pérez-Ayuso RM, Rigotti A, Villarroel L. Gallbladder disease is associated with insulin resistance in a high risk Hispanic population.JHepatol. 2006 Aug; 45(2):299-305.

28. Nakeeb A, Comuzzie AG, Al-Azzawi H, Sonnenberg GE, Kissebah AH, Pitt HA Insulin resistance causes human gallbladder dysmotility.JGastrointest Surg. 2006 Jul-Aug; 10(7):940-8; discussion 948-9.

\section{How to cite this article?}

K. Arvind, Kalghatgi S., Kulkari M., Vipin T., Kamat V, Study to identify dietary factors and life style patterns responsible for gall stones among north Karnatakapatients . Int J surg Orthopedics. 2017;3(3):76-81.doi:10.17511/ijoso.2017.i03.05. 